\title{
O (im)possível diálogo entre a Teologia e a Cultura Brasileira: uma aproximação entre o Ministério Pastoral e a tarefa educacional na vida do Rev. Erasmo Braga
}

Antonio Carlos Anacleto

\section{Resumo}

Ainda que desconhecido na história oficial o ministro presbiteriano e educador Erasmo Braga ofereceu à sociedade brasileira uma grande contribuição social e deixou um importante legado voltado à área da educação. $\mathrm{Na}$ sua contribuição encontra-se difundida uma clara cosmovisão reformada que foi determinante na maneira pela qual via a sociedade brasileira e o papel que entendia ter a educação na transformação e progresso desta sociedade. Para Erasmo Braga a educação deveria ser a forma como o protestantismo se infiltraria de modo gradual e definitivo na sociedade brasileira do início do século XX e a transformaria de forma integral. Nesta contribuição de Erasmo Braga se pode destacar seus inúmeros textos, artigos e livros, as atividades docentes em diversos órgãos, a organização e atuação junto a várias entidades e instituições que promoviam a educação, mas nenhuma delas aproxima-se ao legado oferecido através da conhecida e reconhecida Série Braga, uma das primeiras "cartilhas" de ensino utilizadas no período republicano e que perdurou até meados do século XX.

Palavras-chave: Erasmo Braga, Educação, Série Braga, Teologia. 


\begin{abstract}
Still unknown of the official history, the Presbyterian minister and educator Erasmo Braga offered the Brazilian society a great social contribution and left an important legacy back to the area of education. In its contribution is clearly a widespread Reformed worldview that was dominant in the manner in which he saw the Brazilian society and the role that education be understood in the transformation and progress of society. For Erasmo Braga the education should be how the Protestantism gradually and definitive was seep in Brazilian society in the beginning of the twentieth century and transformed fully. In this contribution Erasmo Braga can highlight its numerous texts, articles and books, teaching activities in various organs, the organization and performance with the various entities and institutions that promote education, but none approaches the legacy offered by known and recognized "Série Braga", one of the first "booklets" of teaching used in the republican period and lasted until the mid twentieth century.
\end{abstract}

Keywords: Erasmo Braga, Education, "Série Braga”, Theology.

\title{
Introdução
}

Dentro da historiografia oficial relativa à área da educação, infelizmente alguns autores acabam sendo esquecidos ou menosprezados seja pela efemeridade dos seus escritos, pela pequena repercussão da sua obra ou até mesmo pelo capricho da história. Erasmo Braga é um destes exemplos que foram esquecidos na historiografia oficial da pedagogia brasileira.

Sendo assim, pretende-se abordar a obra escrita deixada pelo ministro presbiteriano e educador Erasmo Braga voltada essencialmente para a área da educação, porém com um maior destaque para a conhecida Série Braga, sua principal obra nesta área. Deste modo enfatiza-se a limitação desta pesquisa diante do vasto material escrito apresentado pelo autor. Porém, ainda assim, destaca-se que neste momento também enfatizar-se-á as principais influências da atuação de Erasmo Braga como professor e seu legado escrito e institucional.

Dentre a ampla obra de Erasmo Braga nota-se que o mesmo empenhouse em larga escala tanto em temas voltados para a educação geral como a religiosa. Naturalmente, na pesquisa em questão a ênfase se dará unicamente à primeira área. 
Um questionamento primário é quanto ao tipo de contribuição que um religioso pode oferecer à educação. Merece destaque o fato de a educação ser um dos temas de maior destaque no pensamento religioso-reformado ${ }^{1}$, vertente na qual Erasmo Braga se alinha.

A educação é uma das áreas que ganha maior notoriedade social na Reforma Protestante do século $\mathrm{XVI}^{2}$. Pode-se também destacar o interesse dado a mesma através da atuação de reformadores religiosos e sociais como Martinho Lutero, na Alemanha, e João Calvino, principalmente na cidade suíça de Genebra ${ }^{3}$.

Ainda como exemplificação deste fato pode-se destacar a revolução educacional que a Reforma Protestante aliada ao movimento humanista trouxeram à Europa Ocidental em meados do século XVI ${ }^{4}$.

Contrapontuando o movimento religioso reformado que chegou ao Brasil no século XIX, a situação da educação brasileira neste período pode ser descrita através da relação entre Igreja Católica e Estado. Desde o descobrimento do país em 1500 a educação regular sempre esteve sobre a direção da Igreja Católica Apostólica Romana (ICAR) no Brasil, por meio da atuação dos jesuítas e sua metodologia tradicionalista de ensino.

Este domínio teve o seu término oficial com a Proclamação da República no ano de 1889 e a designação constitucional do Estado Laico pela constituição republicana deste ano. Ressalta-se, porém que ao fim desta relação ainda não existiam parâmetros claros para a educação a ser desenvolvida no Brasil ${ }^{5}$.

Neste período pode-se citar ainda a entrada do protestantismo norteamericano no Brasil, que trouxe como uma de suas ferramentas evangelísticas a educação, através da fundação de escolas, fato muito comum, por exemplo, entre os presbiterianos e batistas ${ }^{6}$. Vê-se assim que o tema educação não é estranho ao protestantismo, tanto ao consolidado protestantismo norte-

\footnotetext{
${ }^{1}$ COSTA, Hermisten Maia Pereira da. Raízes da Teologia Contemporânea. Cultura Cristã, São Paulo, 2004, pp. 85-117.

${ }^{2}$ LINDENBERG, Carter. As reformas na Europa. São Leopoldo (RS), Sinodal, 2001, pp. 438-439.

3 BIÉLER, André. O pensamento econômico e social de Calvino. São Paulo, Casa Editora Presbiteriana, 1990, pp. 63-68.

${ }^{4}$ FERREIRA, Edjéce Martins. A ética de Calvino. Recife, Presbitério de Pernambuco, 1988, p. 95.

${ }^{5}$ MENDONÇA, Antônio Gouvêa. A 'questão religiosa': Conflito Igreja vs Estado e expansão do protestantismo. In MENDONÇA, Antônio Gouvêa \& VELASQUES FILHO, Prócoro. Introdução ao Protestantismo no Brasil. São Paulo, Loyola, 1990, p. 61.

${ }^{6}$ RIBEIRO, Boanerges. Protestantismo e cultura brasileira: Aspectos culturais da implantação do protestantismo no Brasil. São Paulo, Casa Editora Presbiteriana, 1981, pp. 183-198.
} 
americano, como ao ainda embrionário protestantismo brasileiro, e tampouco as igrejas cristãs de linha reformada.

Aproximando-se do tema central desta pesquisa, a temática da educação é de grande interesse para o ministro presbiteriano e professor Erasmo Braga tanto que tal temática sempre esteve presente em seus escritos. Braga acreditava que uma educação de qualidade e com princípios e motivações corretas, morais e piedosas poderiam trazer grandes transformações para uma nação como o Brasil ${ }^{7}$.

Pode-se dizer que dentro da sua cosmovisão reformada, vertente à qual Braga pertencia, são as igrejas protestantes que possuem este fundamento e, por isso, devem oferecê-lo como parte do seu serviço espiritual e social à comunidade brasileira ${ }^{8}$.

Ainda nesta seção introdutória vale ser citado o fato de já existirem, ao menos, duas pesquisas que tratem sobre este personagem e sua influência voltada à área da educação. Cronologicamente, em primeiro lugar cita-se a tese do Dr. Alderi de Souza Matos The Life and thought of Erasmo Braga, a brazilian protestant leader, posteriormente publicada no ano de 2008 pela editora Cultura Cristã sob o título Erasmo Braga, o protestantismo e a sociedade brasileira. Cita-se ainda a dissertação da Ms. Roseli de Almeida Massoti sob o título Erasmo Braga e os valores protestantes na educação brasileira.

\section{O homem: Erasmo Braga}

Erasmo Braga nasceu no ano de 1877 na cidade de Rio Claro, na época uma pequena cidade com cerca de 2500 habitantes $^{9}$. De família presbiteriana, sendo inclusive filho do ministro presbiteriano João Ribeiro de Carvalho Braga, Erasmo destacou-se na sociedade brasileira do final do século XIX e início do século XX pela sua erudição, capacidade de dialogar com diferentes áreas e, principalmente, de influenciá-las com a sua visão do reino de Deus.

\footnotetext{
${ }^{7}$ BRAGA, Erasmo \& GRUBB, Keneth G. The republico of Brazil - A survey of the religious situation. Londres (UK), Nova York (USA) \& Toronto (CAN), World Dominion Press, 1932, pp. 132-133.

${ }^{8}$ Ibid, p. 133.

${ }^{9}$ MATOS, Alderi Souza de. Erasmo Braga, o Protestantismo e a Sociedade Brasileira. São Paulo, Cultura Cristã, 2008, pp. 135-144.
} 
Munido de uma clara cosmovisão teísta e com princípios alinhados com os valores reformacionais pode-se afirmar que Braga marcou a sociedade brasileira ao oferecer seus valorosos serviços a diversas causas, entre elas a área educacional, onde deixou um importante legado ${ }^{10}$.

Como parte da definição do homem Erasmo Braga, vale ressaltar a influência que ele recebera de dois pastores-professores, Rev. João Fernandes Dagama e seu pai, que criaram uma espécie de escola-internato para crianças de 6 à 13 anos na pequena cidade de Rio Claro e foram professores da mesma. Neste mesmo período sua mãe também foi professora desta escola.

Posteriormente na cidade de São Paulo J. R. Carvalho Braga, pai de Erasmo, foi também professor na Escola Americana e no Colégio Morton, uma escola particular dirigida pelo missionário norte-americano Rev. George Nash Morton.

Ainda na sua infância, a família Braga mudou-se para Botucatu, onde permaneceu por muitos anos. Nesta cidade Erasmo terminou seus estudos primários. Outro fato curioso que revela o despertar prematuro da vocação docente de Erasmo Braga ocorreu ainda na sua infância onde também deu aulas como assistente de sua mãe na cidade de Botucatu.

Já no ano de 1890, com 13 anos, Erasmo é enviado para a capital da província, São Paulo, onde continuou seus estudos na Escola Americana, proporcional à High School dos EUA, e, posteriormente, no Seminário Presbiteriano ${ }^{11}$.

\section{A atuação do Professor Erasmo Braga na sociedade brasileira}

Erasmo Braga deixou vasta obra voltada para questões pedagógicas e docentes principalmente por meio de artigos e palestras nas quais discute alguns conceitos teóricos da educação, como, por exemplo, a sua importância para o desenvolvimento do ser humano e da sociedade ao seu redor e os desafios que a mesma deveria enfrentar nos tempos modernos. Porém uma grande contribuição do professor Braga voltada a esta área é essencialmente prática por meio de suas experiências como docente ${ }^{12}$.

Pode-se destacar neste legado a sua participação como docente por várias décadas em colégios regulares como o Mackenzie College, Colégio Progresso,

\footnotetext{
${ }^{10}$ FERREIRA, Júlio Andrade. Profeta da Unidade - Erasmo Braga, uma vida a descoberto. Petrópolis, Vozes, 1975, pp. 86-90.

${ }^{11}$ MATOS, 2008, op. cit. pp. 144-154.

${ }^{12}$ Ibid, pp. 243-260.
} 
na cidade fluminense de Niterói, e o tradicionalíssimo Colégio Culto à Ciência, também conhecido como Ginásio do Estado, localizado na cidade de Campinas, interior do Estado de São Paulo.

Braga também foi professor em órgãos voltados para a preparação de pastores, como o Seminário Presbiteriano e o Seminário Unido, localizados respectivamente nas cidades de Campinas e Rio de Janeiro ${ }^{13}$.

A carreira do professor Erasmo começou ainda cedo, pois com apenas 24 anos de idade ele foi trazido de Niterói para lecionar no Mackenzie College e no Seminário Presbiteriano.

Além da atividade docente a influência do professor Braga na sociedade brasileira pode ser sentida também nos diversos órgãos ou instituições que participou ou colaborou na sua organização e consolidação ${ }^{14}$.

Cronologicamente, em primeiro lugar, pode-se citar a fundação da filial paulistana da Associação Cristã de Moços (ACM) juntamente com outros estudantes do Seminário Presbiteriano, a segunda a ser criada no Brasil no ano de 1896.

Em 1903, já com 26 anos, juntamente com alguns intelectuais paulistanos o professor Braga cria a Sociedade Científica de São Paulo, da qual fora por vários anos $1^{\circ}$ secretário. No ano 1908 Braga é aceito como membro do Centro de Ciências, Letras e Artes de Campinas.

Muito sugestivo para o professor Braga é o ano de 1909 no qual ele publica a sua primeira obra, o Glossário Hebreu-Português, obra esta que permitiu a sua posterior aceitação como membro da Sociedade Acadêmica de História Internacional, sediada em Paris. Neste mesmo ano ele participa também da fundação da Academia Paulista de Letras e é convidado à lecionar no Colégio Culto à Ciência, na cidade de Campinas.

Já no ano de 1927, no Rio de Janeiro, Erasmo foi convidado a tornarse membro do Rotary Club, convite este que foi prontamente atendido, pois acreditava que nele poderia ganhar apoio para servir à comunidade brasileira e alcançar outras pessoas para este serviço. Neste mesmo ano, e como consequência da sua profunda amizade com o destacado cientista Vital Brasil e o educador Anísio Teixeira, Erasmo filiou-se à Sociedade de Geografia do Rio de Janeiro e à Associação Brasileira de Educação.

Vê-se que a participação do professor Erasmo Braga na sociedade brasileira deu-se tanto na tarefa docente como na sua participação ativa em

${ }^{13}$ FERREIRA, 1975, op. cit. p. 143.

${ }^{14}$ Ibid, p. 144. 
organizações e intituições que defendiam ou promoviam a questão educacional no Brasil e lutavam pelo seu progresso como meio de transformação social e aceleração do crescimento nacional ${ }^{15}$.

\section{A Série Braga - O legado escrito do Professor Erasmo}

Entre toda a sua vasta e ampla contribuição, destaca-se como o maior e mais importante legado oferecido à sociedade brasileira pelo ministro presbiteriano $\mathrm{e}$ educador Erasmo Braga a reconhecida Série Braga. Esta coletânea era composta de um conjunto contendo quatro livros voltados para a antiga escola primária, os atuais primeiros cinco anos do ensino fundamental, e nesta série dava-se um grande destaque para o ensino, o desenvolvimento e a prática da leitura ${ }^{16}$.

Esta série, em seu tempo, revolucionou a didática do ensino da leitura no Brasil ao se apresentar com um espírito otimista, cívico-patriótico e ao mesmo tempo infundir na mente de seus leitores princípios de piedade e moralidade cristã. $\mathrm{O}$ legado moral não menosprezou o valor pedagógico da obra, pelo contrário via-se uma contribuição paritária neste trabalho, pois: "Toda uma geração de educandos aprendeu a ler nas cartilhas da Série Braga sendo (re) formados por ela" 17 .

A Série Braga foi publicada pela primeira vez no ano de 1919 pela Companhia Melhoramentos e permaneceu sendo usada no Brasil por, pelo menos, 40 anos, alcançando mais de cem edições e foi difundida em praticamente todos os estados da federação. Na visão da Associação Brasileira de Educação (ABE), a Série Braga tinha como um dos seus objetivos além do ensino a formação do caráter do indivíduo ${ }^{18}$.

Ainda destacando a importância e o caráter inovador desta coletânea para a pedagogia brasileira, pode-se afirmar quanto a Série Braga a mesma era organizada em torno de alguns temas principais e não disciplinas, padrão presente em todas as obras pedagógicas usadas neste período no Brasil. Os principais temas eram: Civismo, boas maneiras nas atividades domésticas, família, direito ao lazer, cuidado com os animais domésticos, conhecimento científico,

\footnotetext{
${ }^{15}$ MASSOTI, Roseli de Almeida. Erasmo Braga e os valores protestantes na educação brasileira. Dissertação (Mestrado em Ciências da Religiao) São Paulo, Mackenzie, 2007, p. 164.

${ }^{16}$ Ibid, idem.

${ }^{17}$ Ibid, p. 71.

${ }^{18}$ Ibid, pp. 75-80.
} 
riquezas naturais, direitos e deveres, educação e moralidade. Para atingir tantos e tão variados temas Braga usava textos de cunho próprio, mas também citou mais de uma centena de autores, entre os quais podemos destacar Olavo Bilac, Casimiro de Abreu, José Bonifácio, Castro Alves, Vital Brasil, Gonçalves Dias, Machado de Assis, Ruy Barbosa, entre outros ${ }^{19}$.

Por fim, a Série Braga destaca-se na pedagogia brasileira por apresentar um novo modelo de educação voltada para o ser humano e para a vida. Dentro de um período onde a ênfase do sistema educacional era o conteúdo dentro de uma rígida disciplina, isto é, os ideais da escola tradicionalista implantada pelos jesuítas, Erasmo Braga apresentou nesta série como ênfase o educando e o seu desenvolvimento de maneira integral ${ }^{20}$ (FERREIRA 1975:99-102).

$O$ reconhecimento desta grandiosa obra pode ainda ser destacado pela sua tradução para o idioma japonês, a fim de ser utilizada para orientação de um grupo de imigrantes no aprendizado da língua portuguesa, e também pelo convite que o próprio Erasmo recebeu no ano de 1930 para participar de uma comissão civil, juntamente com os maiores educadores da época, que veio a dar sugestões ao governo brasileiro quanto a uma proposta de reformulação do sistema de educação pública primária e secundária ${ }^{21}$ (FERREIRA 1975:116-119)

\section{Considerações Finais}

Erasmo Braga foi influenciado desde a infância a dar importância à educação e aos valores protestantes e reformados que podem ser apresentados juntamente a ela, valores estes, que segundo o próprio Braga, podem transformar desde um indivíduo, uma sociedade, até um país.

Braga participou ativamente da sociedade brasileira como educador, seja na categoria de professor de escolas e colégios, em atividades administrativas em institutos e órgãos ligados à educação, ou ainda com palestras e artigos sobre este tema.

A Série Braga, obra máxima oferecida por Erasmo, com mais de cem edições e usada praticamente em todo o Brasil por cerca de 40 anos era tão comum em solo pátrio que fê-la participar de uma expressão popular em meados do século passado: Tão velho como a Série Braga, expressão esta

\footnotetext{
${ }^{19}$ Ibid, pp. 137-162.

${ }^{20}$ FERREIRA, 1975, op. cit. pp. 99-102.

${ }^{21}$ Ibid, pp. 116-119.
} 
que assinalava a existência da série de leituras primárias, sua excelência, novidade, amplitude, e o fato de mesma sendo tão antiga não parecia sair do uso nas escolas.

Naturalmente a obra e a contribuição de Erasmo Braga não puderam ser totalmente abarcadas neste trabalho, porém como síntese desta contribuição toma-se como exemplo a Série Braga. Acerca da sua ideologia, ponto destacado no pensamento de Erasmo Braga, para Erasmo a escola deveria ter: "Condições de produzir caráter, valorizar a vida, desenvolver o espírito coopertativo e a cortesia, recrear, ou melhor, re-criar o corpo e a alma pela saúde física, mental e espiritual, integrando a arte e a moral no processo da re-criação do indivíduo"22. Eis o grande motivador para a produção desta coletânea.

Por estes fatos vê-se a relevância deste personagem na questão educacional e sua capacidade de oferecer um diálogo positivo e construtivo da religião cristã-protestante-reformada com a cultura e a sociedade brasileira.

\section{Referências Bibliográficas}

BIÉLER, André. O pensamento econômico e social de Calvino. São Paulo, Casa Editora Presbiteriana, 1990.

BRAGA, Erasmo \& GRUBB, Keneth G. The republico of Brazil - A survey of the religious situation. Londres (UK), Nova York (USA) \& Toronto (CAN), World Dominion Press, 1932.

FERREIRA, Edjéce Martins. A ética de Calvino. Recife, Presbitério de Pernambuco, 1988.

FERREIRA, Júlio Andrade. Profeta da Unidade - Erasmo Braga, uma vida a descoberto. Petrópolis, Vozes, 1975.

LINDENBERG, Carter. As reformas na Europa. São Leopoldo (RS), Sinodal, 2001.

MASSOTI, Roseli de Almeida. Erasmo Braga e os valores protestantes na educação brasileira. Dissertação (Mestrado em Ciências da Religiao) São Paulo, Mackenzie, 2007.

MATOS, Alderi Souza de. Erasmo Braga, o Protestantismo e a Sociedade Brasileira. São Paulo, Cultura Cristã, 2008.

MENDONÇA, Antônio Gouvêa. A 'questão religiosa': Conflito Igreja vs

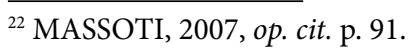


Estado e expansão do protestantismo. In MENDONÇA, Antônio Gouvêa \& VELASQUES FILHO, Prócoro. Introdução ao Protestantismo no Brasil. São Paulo, Loyola, 1990.

RIBEIRO, Boanerges. Protestantismo e cultura brasileira: Aspectos culturais da implantação do protestantismo no Brasil. São Paulo, Casa Editora Presbiteriana, 1981.

\section{Antonio Carlos Anacleto}

Bacharel em Teologia pelo Seminário Presbiteriano do Sul (2004-2007) e pela Universidade Presbiteriana Mackenzie (2009). Atualmente cursa o programa de Pós-Graduação Strictu Sensus em Ciências da Religião pela Universidade Presbiteriana Mackenzie.

Artigo Recebido em 19/08/2011

Artigo Aprovado em 23/11/2011 